\title{
Insight into the use of tympanic temperature during target temperature management in emergency and critical care: a scoping review
}

Michela Masè ${ }^{1,2+}$, Alessandro Micarelli ${ }^{1,3+}$, Marika Falla ${ }^{1,4}$, Ivo B. Regli ${ }^{1,5}$ and Giacomo Strapazzon ${ }^{1 *}$ (D)

\begin{abstract}
Background: Target temperature management (TTM) is suggested to reduce brain damage in the presence of global or local ischemia. Prompt TTM application may help to improve outcomes, but it is often hindered by technical problems, mainly related to the portability of cooling devices and temperature monitoring systems. Tympanic temperature $\left(T_{T y}\right)$ measurement may represent a practical, non-invasive approach for core temperature monitoring in emergency settings, but its accuracy under different TTM protocols is poorly characterized. The present scoping review aimed to collect the available evidence about $\mathrm{T}_{\mathrm{Ty}}$ monitoring in TTM to describe the technique diffusion in various TTM contexts and its accuracy in comparison with other body sites under different cooling protocols and clinical conditions.
\end{abstract}

Methods: The scoping review was conducted following the guidelines of the Preferred Reporting Items for Systematic Review and Meta-Analysis extension for scoping reviews (PRISMA-ScR). PubMed, Scopus, and Web of Science electronic databases were systematically searched to identify studies conducted in the last 20 years, where $\mathrm{T}_{\text {Ty }}$ was measured in TTM context with specific focus on pre-hospital or in-hospital emergency settings.

Results: The systematic search identified 35 studies, 12 performing $T_{T y}$ measurements during TTM in healthy subjects, 17 in patients with acute cardiovascular events, and 6 in patients with acute neurological diseases. The studies showed that $\mathrm{T}_{\mathrm{Ty}}$ was able to track temperature changes induced by either local or whole-body cooling approaches in both pre-hospital and in-hospital settings. Direct comparisons to other core temperature measurements from other body sites were available in 22 studies, which showed a faster and larger change of $\mathrm{T}_{\text {Ty }}$ upon TTM compared to other core temperature measurements. Direct brain temperature measurements were available only in 3 studies and showed a good correlation between $\mathrm{T}_{\mathrm{Ty}}$ and brain temperature, although $\mathrm{T}_{\mathrm{Ty}}$ displayed a tendency to overestimate cooling effects compared to brain temperature.

\footnotetext{
*Correspondence: giacomo.strapazzon@eurac.edu

${ }^{\dagger}$ Michela Masé and Alessandro Micarelli contributed equally to this work. 'Institute of Mountain Emergency Medicine, Eurac Research, Drususallee/ Viale Druso 1, I-39100 Bolzano, Italy

Full list of author information is available at the end of the article
}

C C The Author(s). 2021 Open Access This article is licensed under a Creative Commons Attribution 4.0 International License, which permits use, sharing, adaptation, distribution and reproduction in any medium or format, as long as you give appropriate credit to the original author(s) and the source, provide a link to the Creative Commons licence, and indicate if changes were made. The images or other third party material in this article are included in the article's Creative Commons. licence, unless indicated otherwise in a credit line to the material. If material is not included in the article's Creative Commons licence and your intended use is not permitted by statutory regulation or exceeds the permitted use, you will need to obtain permission directly from the copyright holder. To view a copy of this licence, visit http://creativecommons.org/licenses/by/4.0/ The Creative Commons Public Domain Dedication waiver (http://creativecommons.org/publicdomain/zero/1.0/) applies to the data made available in this article, unless otherwise stated in a credit line to the data. 
Conclusions: $T_{T y}$ was capable to track temperature changes under a variety of TTM protocols and clinical conditions in both pre-hospital and in-hospital settings. Due to the heterogeneity and paucity of comparative temperature data, future studies are needed to fully elucidate the advantages of $\mathrm{T}_{T y}$ in emergency settings and its capability to track brain temperature.

Keywords: Target temperature management, Hypothermia, Ear canal, Tympanic membrane, Cooling devices, Hearables, Cardiac arrest, Stroke, Physiological monitoring, Temperature

\section{Background}

Targeted temperature management (TTM), former therapeutic hypothermia, is an intentional reduction of core temperature to a selected and strictly controlled [1] range of values, which is aimed to improve outcomes in various clinical conditions, including cardiac arrest $(\mathrm{CA})$, traumatic brain injury, stroke, and myocardial infarction [2-4]. By lowering brain temperature, TTM is thought to mitigate brain damage due to global (i.e., CA) or local (i.e., stroke) ischemia, through various mechanisms, including a decrease of cerebral oxygen and glucose consumption, and a reduction of ATP demand $[5,6]$. Current guidelines and recent trials support the use of TTM (in the range of $32-36{ }^{\circ} \mathrm{C}[2,3]$ ) in all CA patients who remain in a state of coma after return of spontaneous circulation (ROSC) [2, 7-11]. The benefit of systemic and selective TTM in stroke patients is supported by recent trials and meta-analyses [12, 13]. Despite a broad consensus on TTM benefits, the application of pre-hospital TTM, for example in out-of-hospital CA, is still controversial [14, 15]. Variable outcomes have been reported [16-18], which may be partially due to limitations in pre-hospital cooling procedures and/or accuracy of temperature monitoring.

Since discrepancies between brain and systemic temperatures have been described, direct monitoring of brain temperature would be desirable for optimal TTM [19]. However, brain temperature measurement techniques are invasive and impractical in most cases and settings. Among different sites for core temperature measurement (e.g., ear canal, rectum, bladder, esophagus, and pulmonary artery) [20], the ear canal (or tympanic membrane) has been proposed as a surrogate measurement site during TTM procedures, especially in pre-hospital and emergency settings, thanks to its accessibility, minimal invasiveness, and fast response. The vasculature pattern of the tympanic membrane is shared with the brain and mediates a thermal equilibrium between the two sites [21-23], which suggests the potential of tympanic temperature $\left(\mathrm{T}_{\mathrm{Ty}}\right)$ to reflect brain temperature. In addition, the vasculature in the tympanic region is minimally influenced by the thermoregulatory vasomotor response, which guarantees adequate flow conditions [24]. In pre-hospital settings, $\mathrm{T}_{\mathrm{Ty}}$ has been shown-albeit with mixed results-to be comparable to invasive temperature measurements at hospital admission [20], providing that insulation from the environment is ensured during measurement [25]. On the other hand, $\mathrm{T}_{\mathrm{Ty}}$ measurement can only be performed if the ear canal is not obstructed (e.g., by blood, cerumen, snow) [20]. $\mathrm{T}_{\mathrm{Ty}}$ can be biased in situations during which blood flow is absent or inadequate [23, 26], and/or it can be affected by anatomical and vascular changes following major ear surgery and large tympanic membrane perforations [27]. $\mathrm{T}_{\mathrm{Ty}}$ accuracy under different TTM protocols (e.g., local versus whole body), TTM phases (e.g., induction versus maintenance), and different pathophysiological conditions need to be further clarified.

This scoping review aims to identify and to summarize all the available evidence over the last 20 years about $\mathrm{T}_{\mathrm{Ty}}$ monitoring in the context of TTM from studies performed either in patients with various acute disorders or in healthy subjects. We describe the level of diffusion of the techniques in various TTM contexts with a focus on pre-hospital and in-hospital emergency settings. We provide indications on the accuracy of tympanic measurements in comparison to other body sites under different TTM phases, cooling protocols, and clinical conditions.

\section{Methods}

The scoping review was conducted following the guidelines of the Preferred Reporting Items for Systematic Review and Meta-Analysis (PRISMA) extension for scoping reviews (PRISMA-ScR) [28].

\section{Eligibility criteria}

The literature search was performed by two authors (AM and $\mathrm{MM}$ ) to identify studies, conducted in the last 20 years, that used $\mathrm{T}_{\mathrm{Ty}}$ during TTM approaches. The search strategy is schematized by the inclusion criteria in Table 1, categorized according to the broad Population-Concept-Context (PCC) mnemonic, recommended for scoping reviews $[29,30]$. The scoping review was focused on pre-hospital and in-hospital emergency settings. We considered both studies testing TTM approaches in healthy subjects and studies where TTM was performed in patients experiencing different emergency conditions. Studies about accidental hypothermia, drug-induced hypothermia, and perioperative and postoperative hypothermia were excluded. The range of TTM temperatures was set to $32-36{ }^{\circ} \mathrm{C}$ according to 
Table 1 Inclusion criteria for the scoping review summarized according to the Population-Concept-Context (PCC) mnemonic, recommended for scoping reviews $[29,30]$

\begin{tabular}{ll}
\hline Population & - Healthy adults (testing of target temperature management approaches). \\
& Patients undergoing target temperature approaches under emergency conditions, including cardiovascular \\
& and neurologic emergencies. \\
& - Any gender. \\
Concept & - Tympanic temperature measurement in the context of target temperature management. \\
Context & $\begin{array}{l}\text { - Testing of target temperature management approaches in healthy subjects; target temperature management } \\
\text { in patients in pre-hospital and in-hospital emergency settings. } \\
\text { - Original peer-reviewed research articles (any study design), published in English in the last } 20 \text { years. }\end{array}$ \\
\hline
\end{tabular}

TTM definition in [2, 3], while studies on normothermia maintenance in patients with fever were not considered. The search was restricted to articles published in English in peer-reviewed journals. No restriction on study design was posed. Abstracts presentations, conference proceedings, and reviews were excluded.

Information sources, search strategy, and study selection A systematic search was performed in PubMed, Scopus, and ISI Web of Science electronic databases to identify primary references from January 2000 to April 2020. The following search strings were used: ("aural" OR "tympanic" OR "epitympanic" OR "ear" OR "ear canal" OR “in-ear" OR "ear-in” OR "earbud” OR "earpiece” OR "earable") AND ("temperature" OR "temperature monitoring" OR "core temperature" OR "core body temperature" OR "body temperature") AND ("hypothermia" OR "hypothermic" OR "therapeutic hypothermia" OR "hypothermic treatment" OR "target temperature management" OR “TTM" OR "body cooling" OR "low temperature" OR "low body temperature"). The database search was followed by a review of the citations from eligible studies. Studies were selected based on title and abstract using the online platform Rayyan [31]. Selected studies were read thoroughly to identify those suitable for inclusion in the scoping review.

\section{Data extraction}

Two reviewers (MM and AM) independently extracted the demographic and experimental data from the selected studies. When disagreement occurred, they reviewed the papers together to reach consensus. For each study, the following relevant information was extracted and summarized: the characteristics of the investigated study population; TTM protocols (body cooling modality, target temperature); the experimental and/or clinical settings of application; the available temperature measurements (presence and location of comparative/ reference temperature measurements in addition to the tympanic one); and the main results of the studies in terms of feasibility of the tympanic measurements and comparability of $\mathrm{T}_{\mathrm{Ty}}$ with core temperature measurements from other body sites.

\section{Results}

\section{Selected studies}

The database search identified a total of 725 relevant references once duplicates were removed (Fig. 1). A total of 681 references were excluded after reading title and abstract and 44 were retrieved for further evaluation. Of these, 9 studies were excluded, because they did not fulfill the inclusion criteria. Following the selection process, 35 studies were included in the scoping review. Of these studies, 12 measured $\mathrm{T}_{\mathrm{Ty}}$ during tests of TTM protocols in healthy subjects, 17 during TTM in patients with acute cardiovascular events, and 6 during TTM in patients with acute neurological disorders. The studies are described in the next paragraphs and summarized in Tables 2,3 , and 4 .

\section{Tympanic temperature measurement during testing of TTM approaches in healthy subjects}

The literature search identified 12 studies that monitored $\mathrm{T}_{\mathrm{Ty}}$ to test the effects of TTM protocols in healthy subjects. These studies are summarized in Table 2 . In 10 studies [32-40, 42], TTM was achieved using surface cooling garments, such as head and neck or chest and thighs cooling devices. In the remaining two studies [41, 43], endovascular cold solutions were used. Comparative core-temperature measurements were present in eight studies [32-39], where rectal/intestinal sites were monitored. Consistently among studies, $\mathrm{T}_{\mathrm{Ty}}$ showed more pronounced changes than rectal [33-35] or intestinal temperature [32]. During chest and thighs surface cooling, the difference between tympanic and rectal temperature was maximal during induction of hypothermia and decreased during its maintenance [36]. Compared to other measurement sites, during head cooling $\mathrm{T}_{\mathrm{Ty}}$ temperature showed lower variations than skin temperature [35] and more reliable data than sublingual temperature measurements [42]. Overall the studies showed that $\mathrm{T}_{\mathrm{Ty}}$ was useful in the validation of novel cooling strategies in healthy subjects, where $\mathrm{T}_{\mathrm{Ty}}$ was able to track temperature variations 


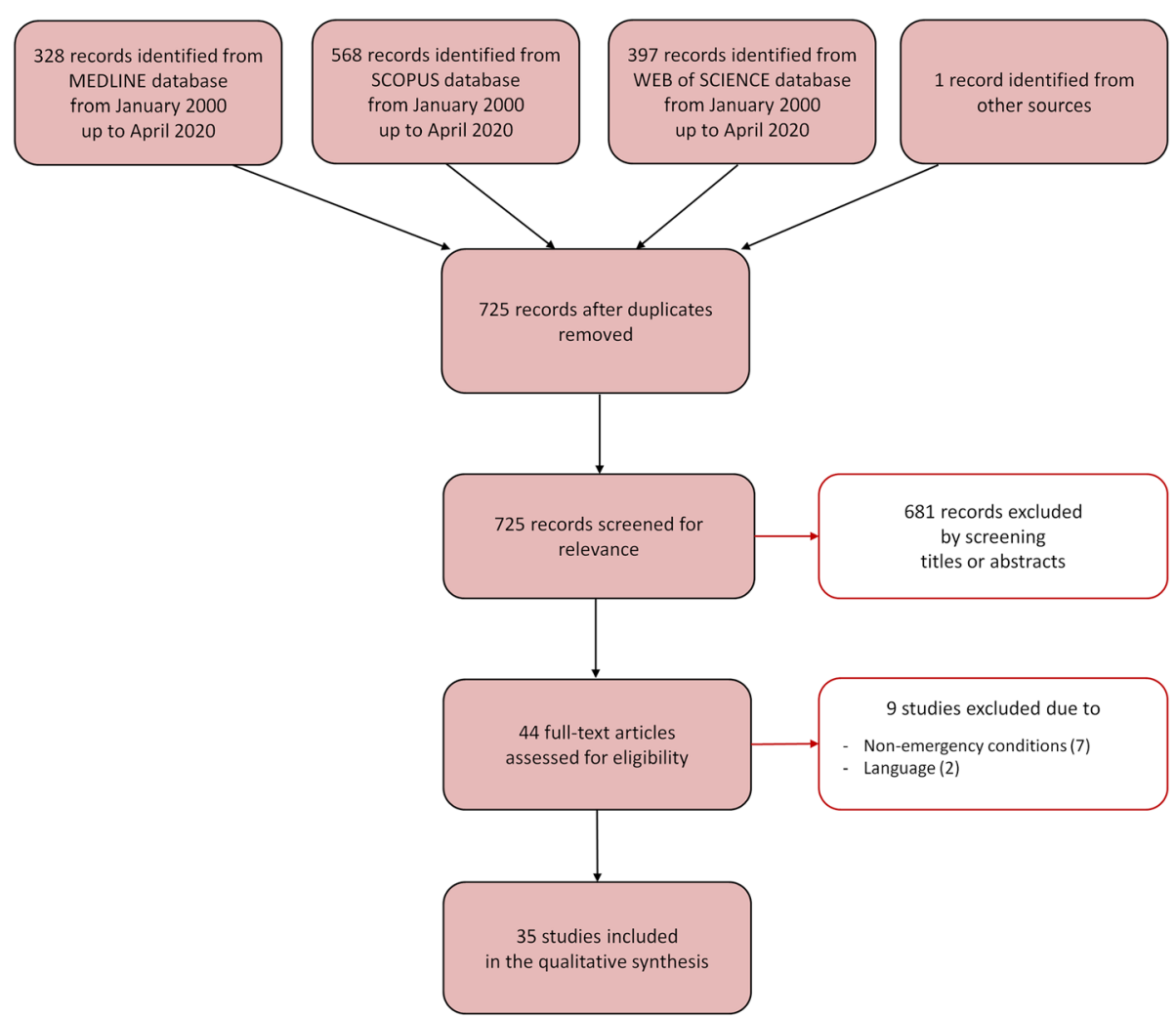

Fig. 1 Selection process for the studies included in the scoping review. The Preferred Reporting Items for Systemic Reviews and Meta-Analyses (PRISMA-SCR) flow diagram depicts the number of records identified, included, and excluded, and the reasons for exclusion, through the different phases of the scoping review

induced by local head and/or neck [32-35, 42] or chest and tights cooling [36-39]. In addition, it was shown to correlate with intracerebral blood flow velocity during mild hypothermia induced by local cooling [39]. In four studies focusing on TTM shivering thresholds [37, 38, 41, 43], $\mathrm{T}_{\mathrm{Ty}}$ was able to identify the shivering threshold during either local $[37,38]$ or endovascular cooling $[41,43]$.

\section{Tympanic temperature measurement during TTM in acute cardiovascular events}

Seventeen studies were identified in which $\mathrm{T}_{\mathrm{Ty}}$ was measured during TTM in patients with acute cardiovascular events. The studies are summarized in Table 3. Fifteen studies [44-58] included patients with CA. TTM was started in a pre-hospital setting in four studies $[45,46,57$, 58], while it was started at the emergency department in the remaining eleven $[44,47-56]$. Two studies $[59,60]$ included patients with ST-segment elevation myocardial infarction undergoing percutaneous coronary interventions and TTM was performed pre-reperfusion $[59,60]$. In one study, the procedure was started in the pre-hospital setting [60]. In all the studies, target temperature was in the range of mild hypothermia $\left(33-34{ }^{\circ} \mathrm{C}\right)$, whereas the TTM cooling procedures and protocols varied among the studies, including (i) local cooling procedures [44-46, 48, $49,58]$, (ii) whole body cooling $[47,57,59,60]$, and (iii) a combination of the two [50-56]. Comparative coretemperature measurements, including esophageal, rectal, bladder, iliac, or pulmonary artery sites, were mostly available for the studies performed in hospital settings [44, 45, $47-51,53-55]$, and provided indications of $\mathrm{T}_{\mathrm{Ty}}$ accuracy in relation to the TTM phases [50, 51]. During local cooling procedures, such as trans-nasal cooling, the tympanic site generally displayed a faster response than the rectal and bladder ones $[44,46]$. The tympanic site showed comparable cooling times with respect to the esophageal site [49], although it showed larger temperature variations in response to the cooling maneuvers $[44,49] . \mathrm{T}_{\mathrm{Ty}}$ showed larger bias compared to esophageal temperature during head and especially head-neck cooling, where it underestimated esophageal $\mathrm{T}$ with an average bias of $-1.65^{\circ} \mathrm{C}$ and $-3.06{ }^{\circ} \mathrm{C}(\mathrm{p}=0.001)$, respectively [54]. During whole body cooling, the tympanic site showed a low average bias $\left(0.021^{\circ} \mathrm{C}\right)$ and high correlation $(\mathrm{r}=0.95, \mathrm{p}<0.0001)$ compared to the esophageal site [47]. Conversely, $\mathrm{T}_{\mathrm{Ty}}$ showed the highest bias in comparison with pulmonary-artery measurements [50,51], resulting in the underestimation of core temperature through the different TTM phases 


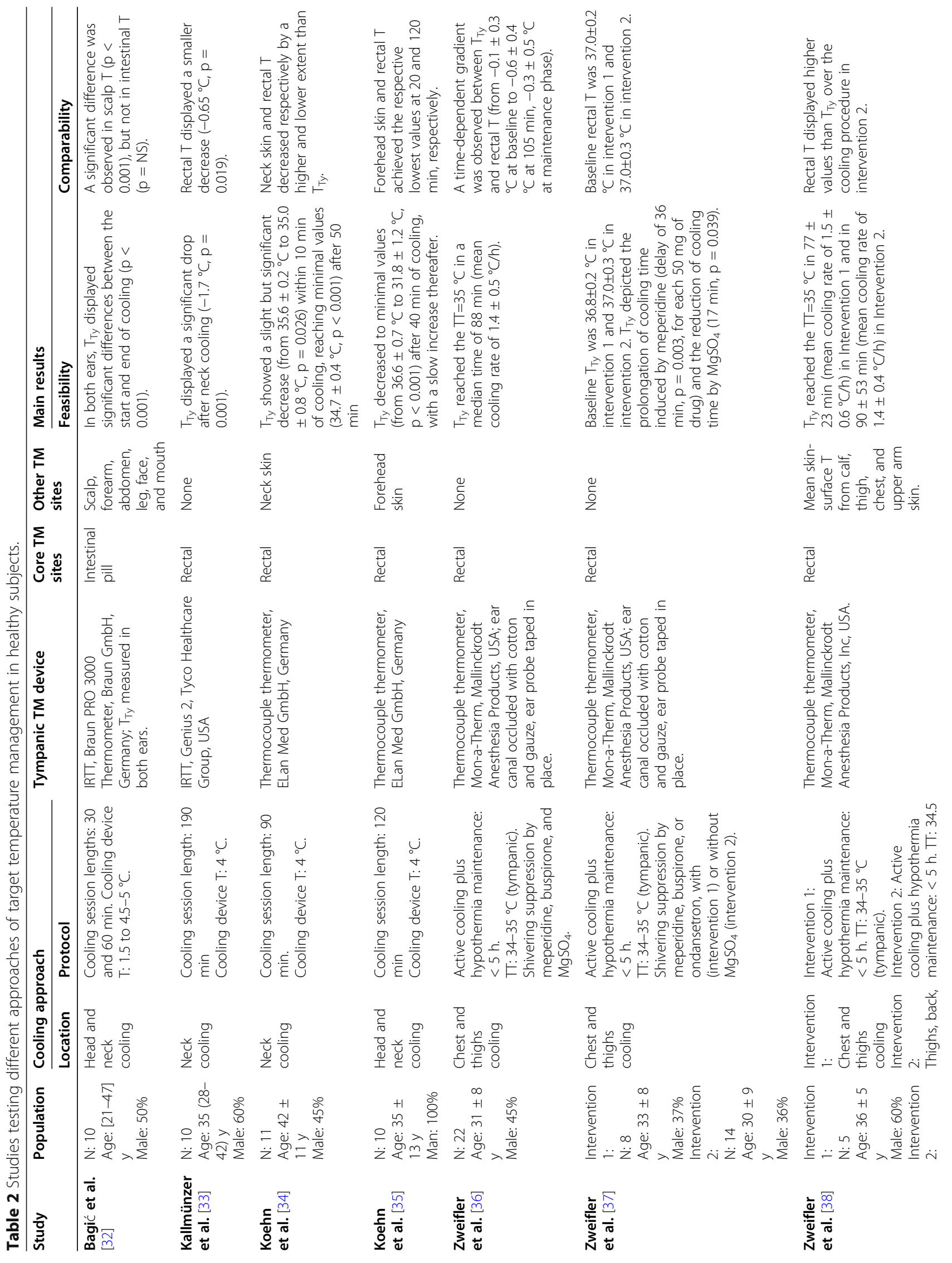




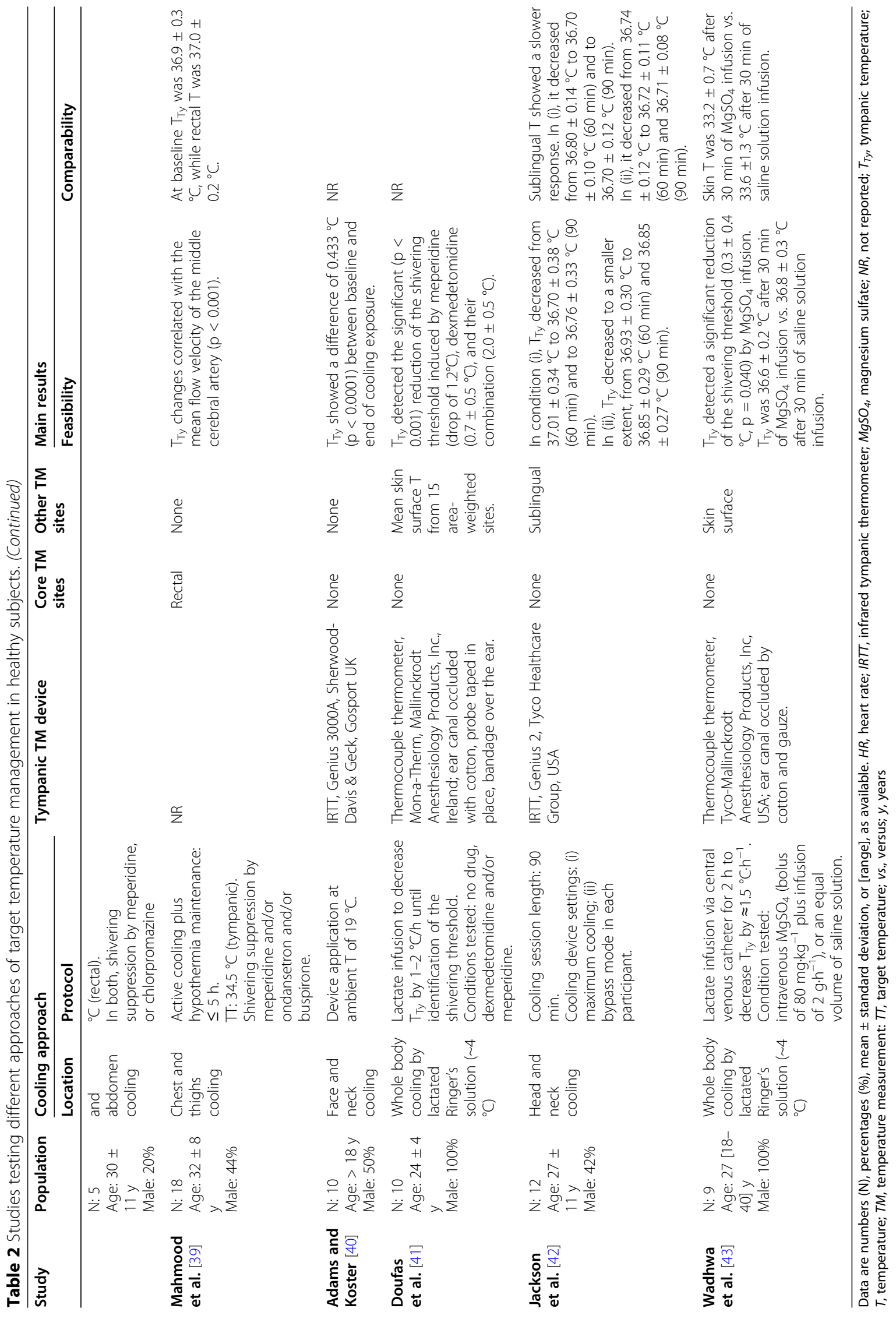




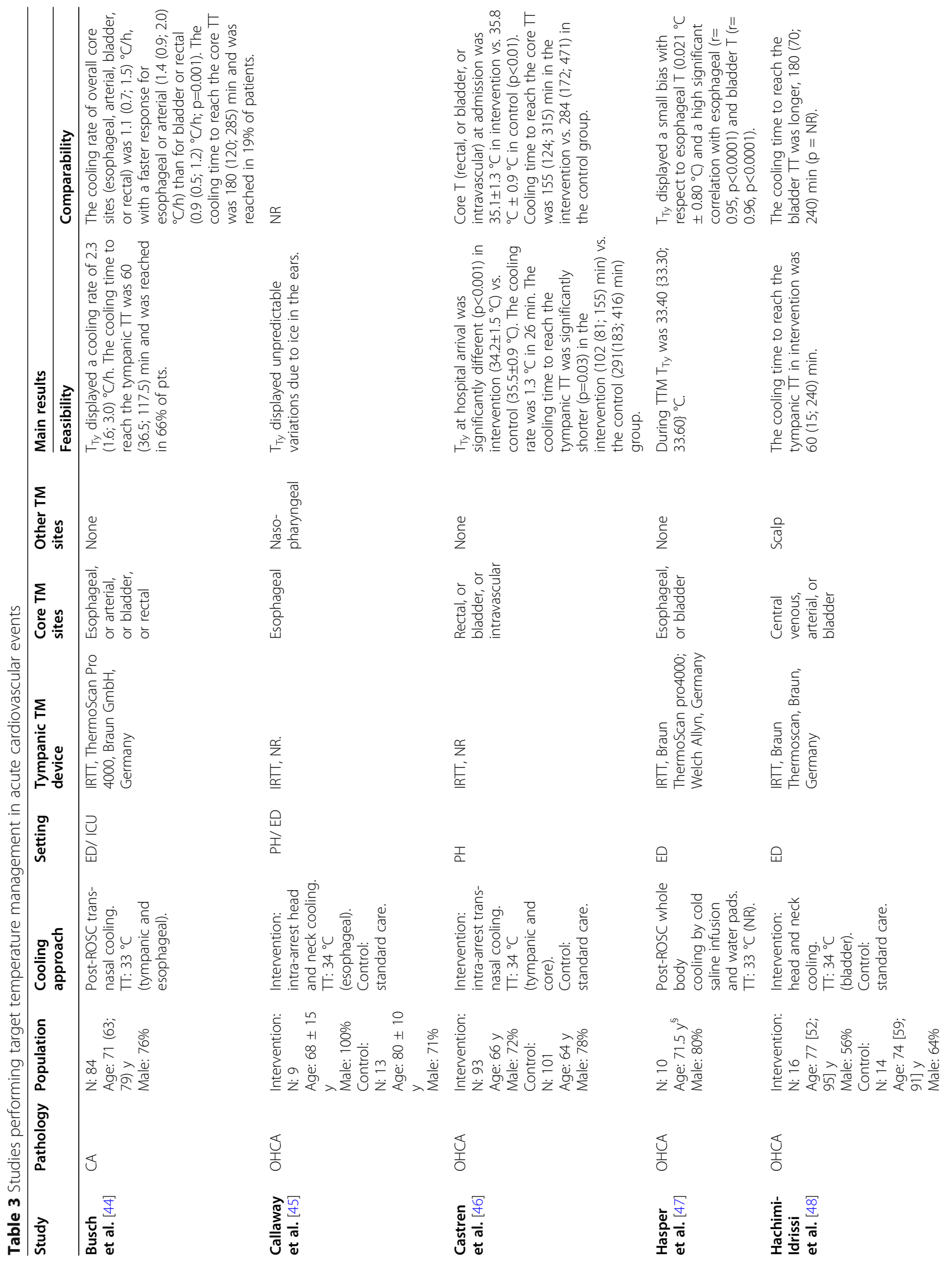




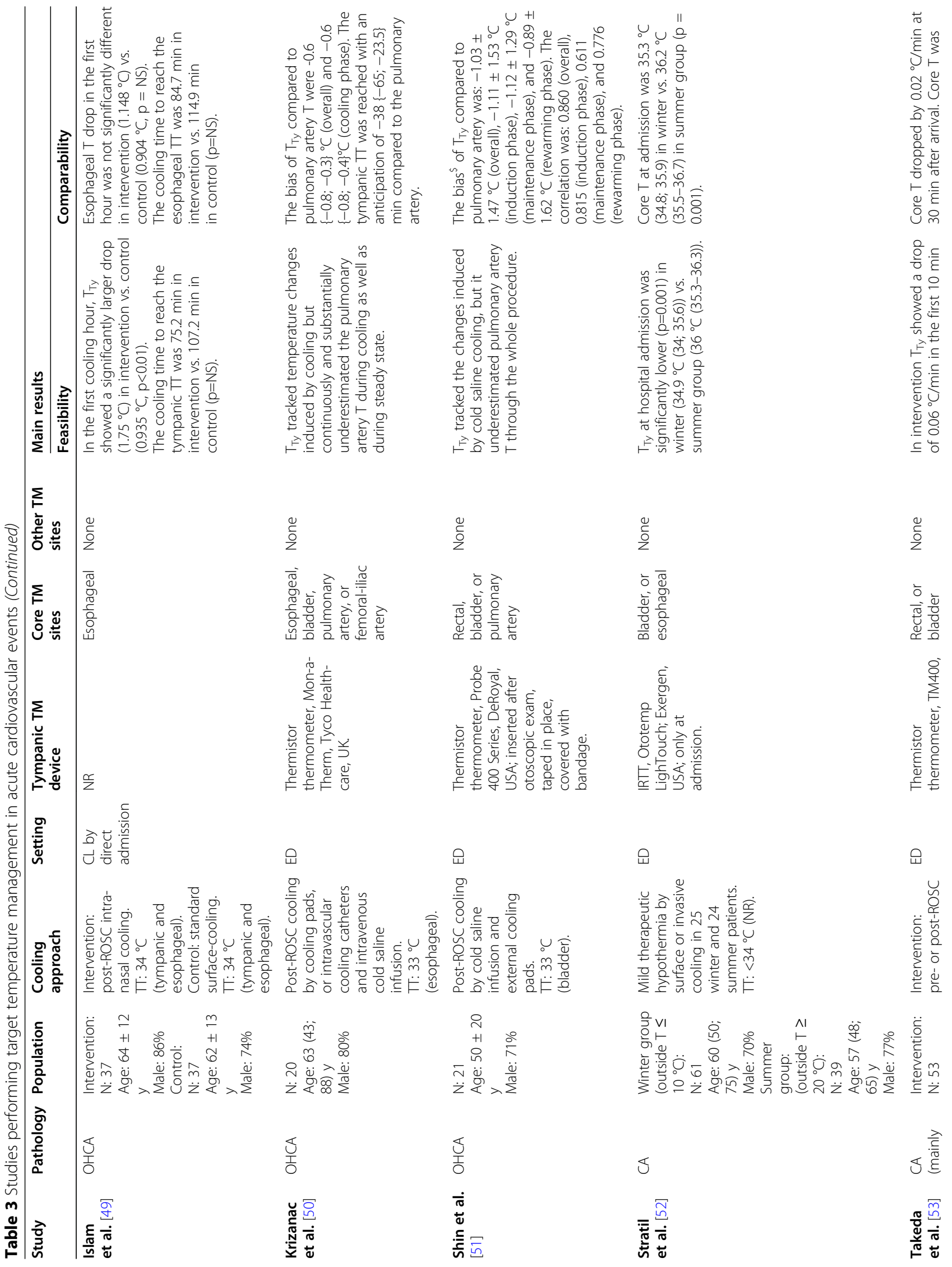




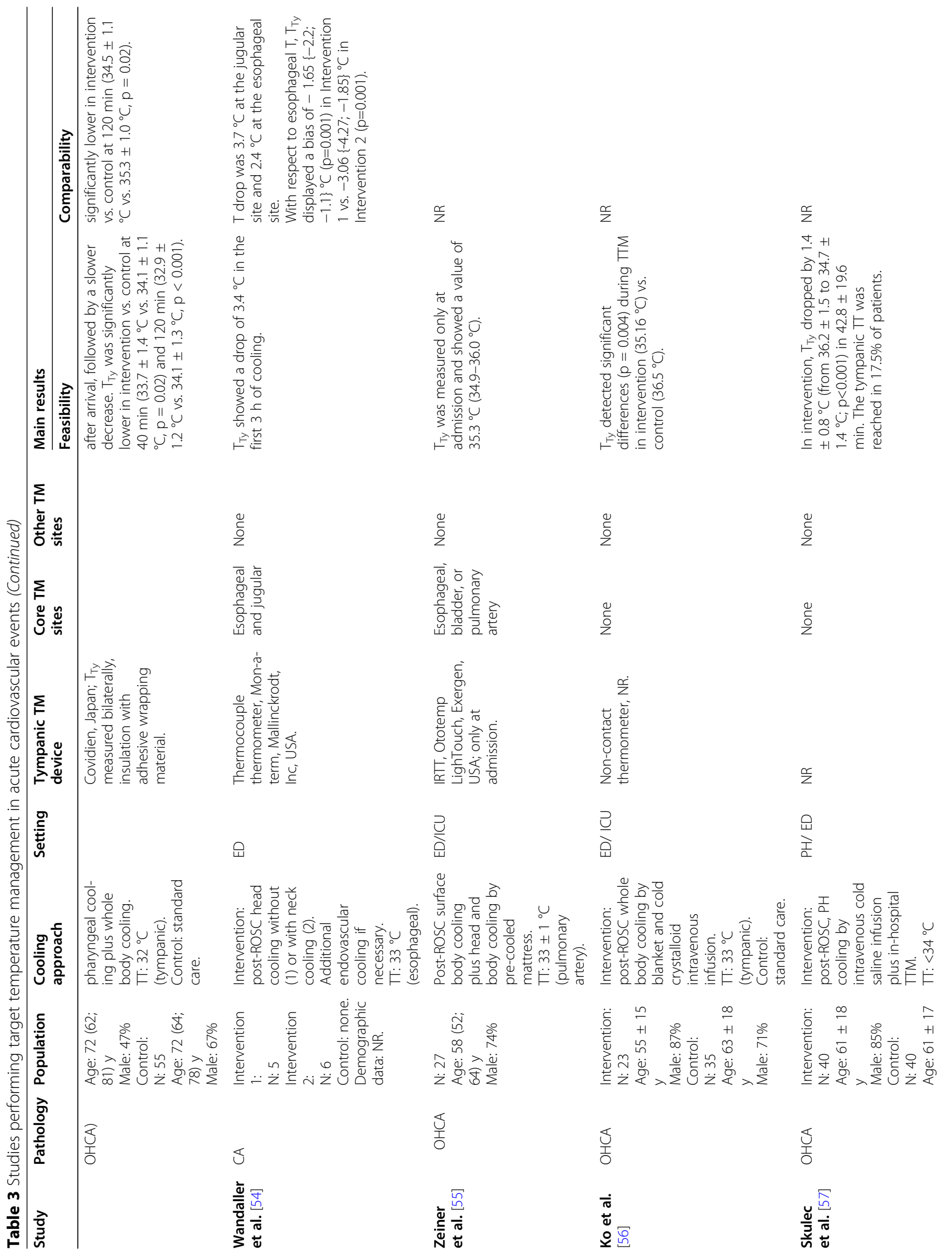




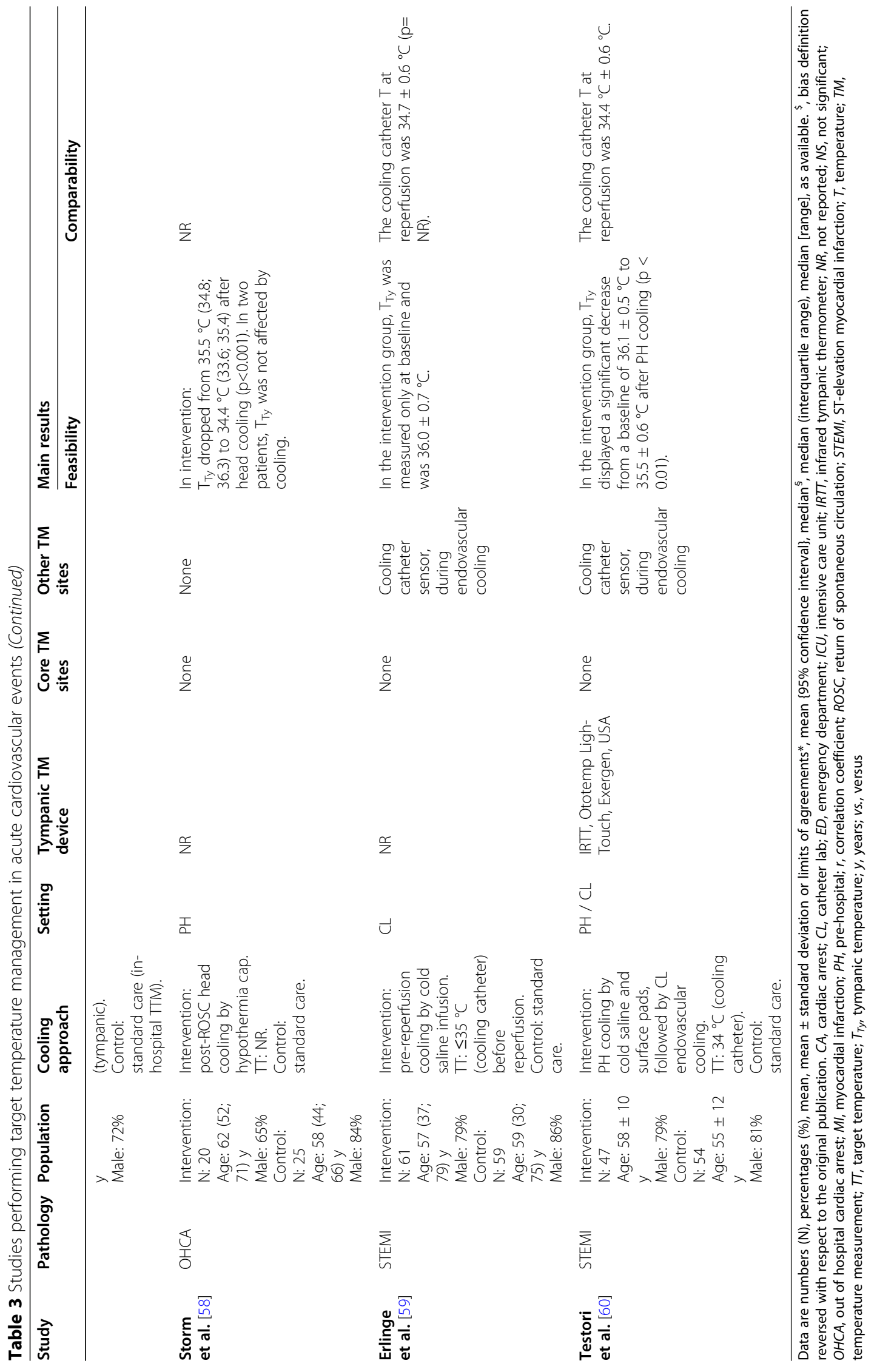




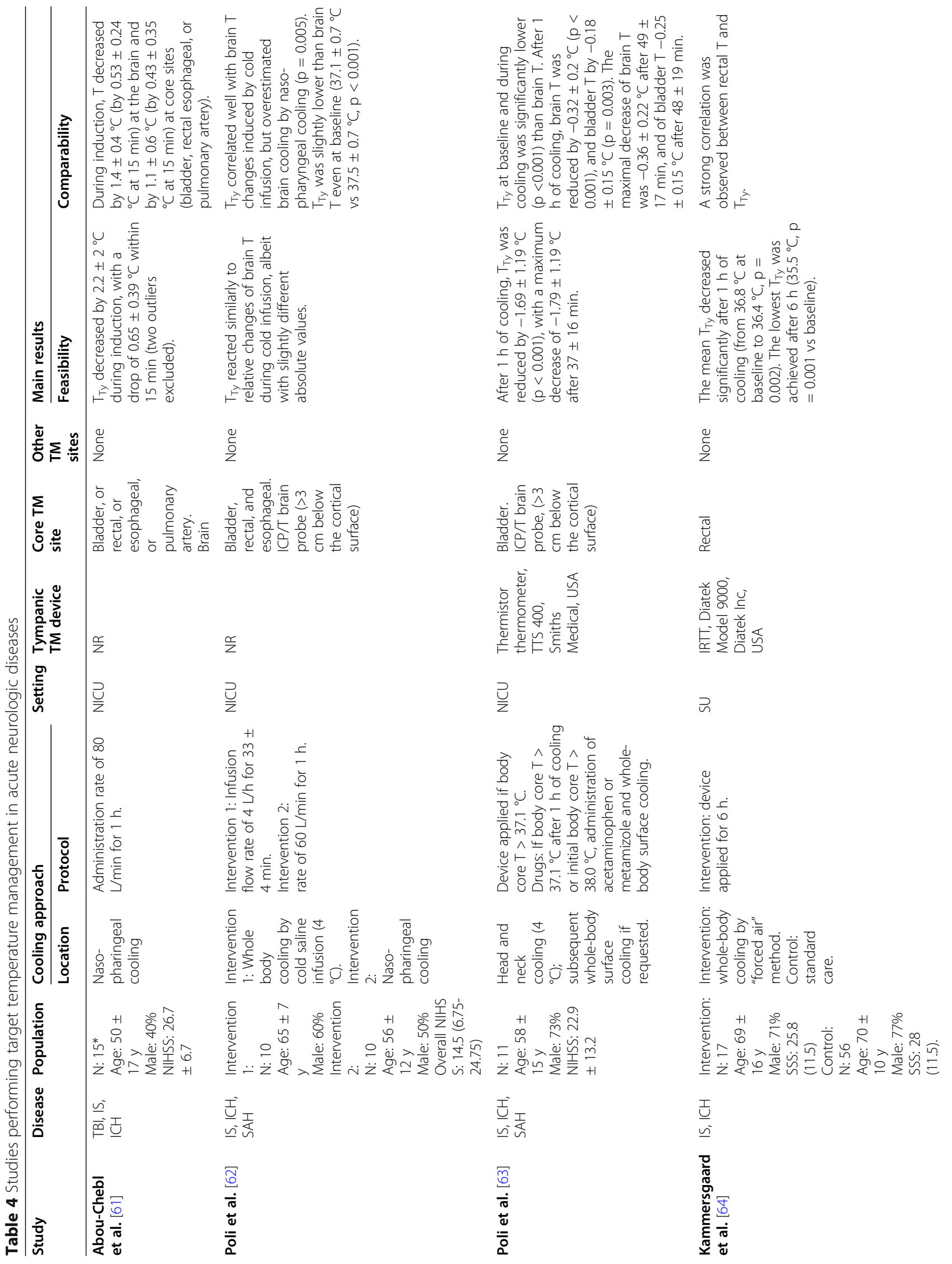




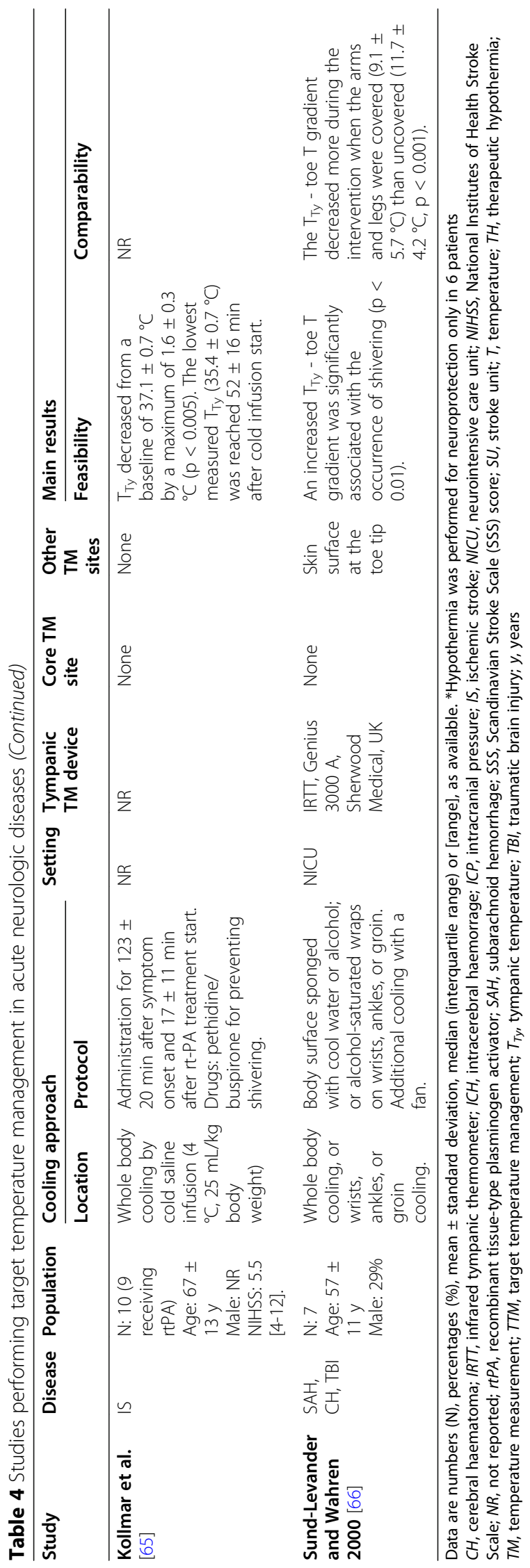


(overall bias of $-0.6{ }^{\circ} \mathrm{C}[50]$ and $-1.03{ }^{\circ} \mathrm{C}$ [51]) and in a shorter cooling-time duration [51]. In pre-hospital settings, $\mathrm{T}_{\mathrm{Ty}}$ was capable of tracking the effects of prompt post-ROSC application of TTM by cold saline infusion [57] or by a hypothermia cap [58] in CA patients, as well as the effects of cold saline and surface pads in patients with acute myocardial infarction [60]. However, tympanic measurements showed to be biased by external factors, such as variations in the environmental temperature [52] or the presence of snow/ice in the ear canal [45]. In the in-hospital setting, tympanic measurements were able to track temperature changes associated with nasal/ pharyngeal or head/neck cooling [44, 48, 49, 53], cold saline infusion $[47,57]$, or a combination of local and whole body cooling [50, 51, 53-56]. In patients with acute myocardial infarction $[59,60]$, the tympanic site was used to complement catheter tip measurements, when the latter were not available.

\section{Tympanic temperature measurement during TTM in acute neurological disorders}

Six studies tracked $\mathrm{T}_{\mathrm{Ty}}$ during TTM in patients with acute neurological disorders, which included ischemic or hemorrhagic stroke, subarachnoid hemorrhage, and cerebral hematoma after traumatic brain injury. The studies are summarized in Table 4. TTM protocols were applied in-hospital in all the retrieved studies. In three studies [61-63], patients were intubated and deeply sedated. TTM protocols differed among the studies in terms of cooling devices, target temperature measurement sites, starting temperature, and target temperature (mostly mild hypothermia). The applied cooling techniques included (i) whole body cooling by intravenous injection of cold saline solutions $[62,65]$ and (ii) local body cooling by nasopharyngeal $[61,62]$ or head/neck cooling devices [63], body surface wraps/sponges [66], and/or the "forced air" method [64]. In most of the studies, comparative core measurements were available for the bladder, rectal, and esophageal sites [61-63, 67], and in one study also for the pulmonary artery [61]. $\mathrm{T}_{\mathrm{Ty}}$ showed a larger drop compared to other core-temperature measurement sites during pharyngeal cooling [61], while it showed strong correlation with rectal temperature during surface cooling by "forced air" method [64]. In three studies [61-63], brain temperature measurements from a probe inserted below the cortical surface were available. $\mathrm{T}_{\mathrm{Ty}}$ correlated well with brain temperature during whole body cooling induced by intravenous cold saline solution in stroke patients, although it displayed lower values already at baseline with a bias of $-0.4{ }^{\circ} \mathrm{C}$ [62]. During nasopharyngeal cooling $[61,62]$ or head and neck cooling [63], $\mathrm{T}_{\mathrm{Ty}}$ overestimated brain cooling, showing a more marked decrease (drop in the first hour of cooling ranging from -1.69 to $-2.2{ }^{\circ} \mathrm{C}$ at the tympanum vs. -0.32 to -1.4
${ }^{\circ} \mathrm{C}$ at the brain), while other core-temperature measurement sites underestimated brain cooling, displaying a lower decrease (temperature drop ranging from $-0.18{ }^{\circ} \mathrm{C}$ to $\left.-1.1^{\circ} \mathrm{C}\right)[61,63]$.

$\mathrm{T}_{\mathrm{Ty}}$ displayed capability to track temperature changes induced by either local or whole cooling. In addition, when used in combination with skin temperature, it depicted the risk of shivering during surface cooling [66].

\section{Discussion}

The main findings of the present scoping review, aimed at assessing the diffusion, feasibility, and accuracy of $\mathrm{T}_{\mathrm{Ty}}$ monitoring during TTM, are: (i) $\mathrm{T}_{\mathrm{Ty}}$ was capable to track temperature changes induced by a variety of TTM approaches, including local or whole body cooling, in both pre-hospital and in-hospital settings and under different clinical conditions; (ii) $\mathrm{T}_{\mathrm{Ty}}$ may have selective advantages for TTM in prehospital settings, where it is often the sole temperature measurement available; and (iii) limited evidence is available about $\mathrm{T}_{\mathrm{Ty}}$ accuracy in relation to reliable core body and brain sites.

\section{Feasibility and performance of $\mathrm{T}_{\mathrm{Ty}}$ monitoring in emergency and critical care}

The evidence provided by the 35 identified studies generally supported the capability of $\mathrm{T}_{\mathrm{Ty}}$ to follow temperature changes induced by either local or wholebody cooling strategies. The most common application fields for $\mathrm{T}_{\mathrm{Ty}}$ were the testing of novel cooling strategies in healthy subjects and the monitoring of TTM in patients with acute cardiovascular events, while applications in patients with acute neurological disorders were sparser. In patients with acute cardiac disease, $\mathrm{T}_{\mathrm{Ty}}$ monitoring was applied in both pre-hospital and in-hospital emergency settings. In the former setting, tympanic monitoring was mostly used as the sole temperature measurement, which may indicate a selective advantage of $\mathrm{T}_{\mathrm{Ty}}$ in this condition. Thanks to its reduced invasiveness and easy application, ear probe measurements may allow prompt TTM initiation [68]. In comparison, esophageal temperature probes usually require an intubated patient and rectal temperature measurements may be not easily accessible [68]. However, factors limiting $\mathrm{T}_{\mathrm{Ty}}$ reliability should be properly considered for an appropriate use of the technique. $\mathrm{T}_{\mathrm{Ty}}$ measurements may be influenced by alterations in the blood flow to the brain, as demonstrated for instance by tilting maneuvers [23]. Therefore, $\mathrm{T}_{\mathrm{Ty}}$ measurements in $\mathrm{CA}$ patients should be considered reliable only after the patient has regained a stable spontaneous circulation. Moreover, pre-hospital studies showed $\mathrm{T}_{\mathrm{Ty}}$ measurements to be affected by external factors, such as variations in the environmental temperature or the presence of snow/ice in 
the ear canal [45]. Consistently, previous studies pointed out the necessity of performing $\mathrm{T}_{\mathrm{Ty}}$ measurements in a clean and dry ear canal and the importance of properly insulating the tympanic probe, especially when operating in settings exposed to environmental factors (e.g., cold, wind) $[25,69]$.

\section{Comparison of the tympanic site versus other core- temperature measurement sites}

In emergency and critical care settings, alternative coretemperature measurement sites are available to track temperature; thus, the performance and eventual advantages of $\mathrm{T}_{\mathrm{Ty}}$ in comparison to other measures need to be evaluated. Tympanic measurements were combined with other measurements in 30 studies [32-39, 41-55, 59-64, 66], of which 22 studies [32-39, 44, 46-54, 61-64] provided a direct comparison with temperatures measured at different core or brain sites. These studies presented heterogeneity in terms of studied population, cooling protocols and devices, tympanic thermometer type (IRTTs or thermistor/thermocouple thermometers), and comparative/reference sites. All these variability factors hindered the calculation of an overall figure of merit for tympanic measurement site. As an additional limitation, rectal temperature was mostly used as comparator among studies. The rectal site has known limitations and a slow response in dynamic conditions [20, 70-72], which is mainly attributed to the buffering influence and heat-sink effect of rectal tissue and stool in the rectum $[73,74]$.

The comparison of $\mathrm{T}_{\text {ty }}$ with the most reliable core sites (i.e., esophageal, jugular, and pulmonary artery sites), available from studies in emergency and critical care settings, showed that $\mathrm{T}_{\mathrm{Ty}}$ performance depended on the cooling protocols and reference site considered. Compared to esophageal temperature, $\mathrm{T}_{\mathrm{Ty}}$ showed comparable cooling times during intranasal cooling [49], and low bias and high correlation during cold saline infusion [47]. A larger bias with esophageal temperature was observed during head and neck cooling [54]. Compared to the pulmonary artery, the tympanic site showed the highest bias during cold saline infusion [50, 51]. Although the pulmonary artery temperature is usually considered as the gold standard core-temperature to guide clinical mild hypothermia $[75,76]$, previous studies have shown that the temperature of the pulmonary artery blood may reflect less well brain temperature when hypothermia is induced or reversed, during either selective head cooling or rapid intravascular cooling [77, 78]. Instead, esophageal temperature responds rapidly to changes in the temperature of the blood perfusing the heart and great vessels [77, 79] and it showed a better relationship with brain temperature when inducing hypothermia and at early TTM, in either selective head or whole-body cooling [77]. The better agreement of $\mathrm{T}_{\mathrm{Ty}}$ with the esophageal than with the pulmonary artery temperature may thus suggest the reliability of $\mathrm{T}_{\mathrm{Ty}}$ to track brain temperature. The capability of $\mathrm{T}_{\mathrm{Ty}}$ to reflect brain temperature is supported by the assumption that the tympanic membrane is supplied by vasculature from the same sources that supply the brain (i.e., branches of the basilar and internal carotid arteries, which join anastomoses with branches of the external carotid artery in the region around and within the tympanic membrane $[21,22,80])$, which guarantees thermal equilibrium between the two sites [23]. However, although $\mathrm{T}_{\mathrm{Ty}}$ is currently the most commonly used non-invasive method for brain temperature estimation [81], being the sole anatomical structure close to the brain that is accessible without surgery $[82,83]$, concerns remain on its accuracy, mainly due to measurement errors, measuring devices, and/or real temperature differences between the ears [80]. In the specific setting of TTM, the present review revealed a gap of evidence in the literature about the capability of $\mathrm{T}_{\mathrm{Ty}}$ to reflect brain temperature. We identified only three studies in acute neurological patients [61-63], which provided comparative direct brain temperature measurements at a single subcortex site. The studies displayed heterogeneity in terms of patient characteristics and underlying disorders, cooling procedures, and target temperature. The results showed a high correlation between $\mathrm{T}_{\mathrm{Ty}}$ and brain temperature during whole body cooling. Nonetheless, $\mathrm{T}_{\mathrm{Ty}}$ generally overestimated brain cooling in either whole body [61, 62] or local body cooling [62], with more severe overestimation during head and neck cooling [63]. Of note, other sites for core-temperature measurements generally underestimated cooling effects [61]. Although these results may suggest the potential of $\mathrm{T}_{\mathrm{Ty}}$ to track brain temperature with similar performance to other more invasive distal measurement sites, the larger response of $\mathrm{T}_{\mathrm{Ty}}$ may result in an overestimation of cooling effects through different TTM phases and thus in a shorter cooling-time duration [51], with the risk for patients to stay outside the ideal temperature range during TTM induction and steady state.

\section{Future perspectives}

Simultaneous measurements at different brain and core temperature sites according to well-defined protocols should be performed during both local and whole-body cooling procedures. The characterization of the spatiotemporal temperature patterns under various TTM approaches by a continuous temperature acquisition through the different TTM phases is desirable. In experimental studies, brain temperature should be monitored at multiple sites, since a single site may not reflect temperature across the brain, especially in the presence 
of head cooling and marked temperature gradients [8486]. The systematic assessment of bias and correlation between $\mathrm{T}_{\mathrm{Ty}}$ and brain or other core-temperature measurement sites and the comparison with therapeutic outcome may allow to define sharp recommendation and safe target ranges for $\mathrm{T}_{\mathrm{Ty}}$ under different TTM applications. $\mathrm{T}_{\mathrm{Ty}}$ performance may be improved with proper recalibration of target temperature values, as $\mathrm{T}_{\mathrm{Ty}}$ often led to an underestimation of core temperature even at baseline but showed a moderate to high correlation with esophageal temperature. Finally, clinical, experimental, and industrial research should synergistically concur to develop wearable temperature trackers [80], able to overcome the limitations of current tympanic thermometers $[25,66,69,80,87]$ and to grant fix probe positioning and protection from external environmental conditions [80]. These developments may improve temperature monitoring and allow early TTM extension under logistically challenging critical conditions.

\section{Conclusions}

The results of the present scoping review provided evidence about the capability of $\mathrm{T}_{\mathrm{Ty}}$ to track temperature changes induced by either local or whole-body cooling in both prehospital and in-hospital TTM applications. However, there is a paucity of studies performing a systematic comparison of $\mathrm{T}_{\mathrm{Ty}}$ performance with reliable core and brain temperature measurement sites, which hinders a thorough evaluation of $\mathrm{T}_{\mathrm{Ty}}$ advantages in emergency settings and of the capability of $\mathrm{T}_{\mathrm{Ty}}$ to track brain temperature. Future experimental and clinical studies should bridge this gap of evidence by providing reliable devices and dedicated temperature ranges for safe application of $\mathrm{T}_{\mathrm{Ty}}$ in TTM and by clarifying the relationship between $\mathrm{T}_{\mathrm{Ty}}$ and brain temperature. Thanks to its easy use and reduced invasiveness, $\mathrm{T}_{\mathrm{Ty}}$ may have selective advantage in pre-hospital settings, when practical limitations may hinder temperature acquisition from more invasive sites.

\section{Abbreviations}

ATP: Adenosine triphosphate; CA: Cardiac arrest; IRTT: Infrared tympanic thermometer; PCC: Population-Concept-Context; ROSC: Return of spontaneous circulation; TTM: Target temperature management;

$\mathrm{T}_{\text {Ty: }}$ Tympanic temperature

\section{Acknowledgements}

The authors thank the Department of Innovation, Research, University and Museums of the Autonomous Province of Bozen/Bolzano for covering the Open Access publication costs.

\section{Authors' contributions}

MM and MA conceived the study, performed the systematic search, extracted and interpreted the data, drafted the manuscript. MF, IBR, and GS concurred to data interpretation and substantively revised the manuscript for important intellectual content. All authors read and approved the final manuscript.

\section{Funding}

The research leading to these results has received funding from the FESR Program 2014-2020 of the Autonomous Province of Bolzano - Alto Adige, under Grant Agreement [513/2019]/Project number [FESR 1114] [Development of innovative sensors for monitoring vital parameters in emergency medicine, MedSENS]

\section{Availability of data and materials}

All the data generated or analyzed during this study are included in the published article.

\section{Declarations}

Ethics approval and consent to participate

Not applicable.

\section{Consent for publication}

Not applicable.

\section{Competing interests}

The authors declare that they have no competing interests.

\section{Author details}

${ }^{1}$ Institute of Mountain Emergency Medicine, Eurac Research, Drususallee/ Viale Druso 1, I-39100 Bolzano, Italy. ${ }^{2}$ IRCS-HTA, Bruno Kessler Foundation, Trento, Italy. ${ }^{3}$ ITER Center for Balance and Rehabilitation Research (ICBRR), Rome, Italy. ${ }^{4}$ Centre for Mind/Brain Sciences, CIMeC, University of Trento, Rovereto, Italy. ${ }^{5}$ Department of Anesthesia and Intensive Care, "F. Tappeiner" Hospital, Merano, Italy.

Received: 3 February 2021 Accepted: 30 May 2021

Published online: 12 June 2021

\section{References}

1. Taccone FS, Picetti E, Vincent J-L. High quality targeted temperature management (TTM) after cardiac arrest. Critical Care. 2020;24(1):6. https://doi.org/10.1186/s13054-019-2721-1.

2. Nielsen $N$, Wetterslev J, Cronberg T, Erlinge D, Gasche $Y$, Hassager $C$, et al. Targeted temperature management at $33^{\circ} \mathrm{C}$ versus $36^{\circ} \mathrm{C}$ after cardiac arrest. N Engl J Med. 2013;369(23):2197-206. https://doi.org/10.1056/NEJMoa131 0519 .

3. Polderman $\mathrm{KH}$, Herold I. Therapeutic hypothermia and controlled normothermia in the intensive care unit: practical considerations, side effects, and cooling methods. Crit Care Med. 2009;37(3):1101-20. https://doi. org/10.1097/CCM.0b013e3181962ad5.

4. Polderman $\mathrm{KH}$. Induced hypothermia and fever control for prevention and treatment of neurological injuries. Lancet. 2008;371(9628):1955-69 https://doi.org/10.1016/S0140-6736(08)60837-5

5. Hypothermia after Cardiac Arrest Study Group. Mild therapeutic hypothermia to improve the neurologic outcome after cardiac arrest. N Engl J Med. 2002:346(8):549-56. https://doi.org/10.1056/NEJMoa012689.

6. Karnatovskaia LV, Wartenberg KE, Freeman WD. Therapeutic hypothermia for neuroprotection: history, mechanisms, risks, and clinical applications. Neurohospitalist. 2014;4(3):153-63. https://doi.org/10.1177/1941874413519802.

7. Evald L, Brønnick K, Duez CHV, Grejs AM, Jeppesen AN, Søreide E, et al. Prolonged targeted temperature management reduces memory retrieval deficits six months post-cardiac arrest: a randomised controlled trial. Resuscitation. 2019;134:1-9 https://doi.org/10.1016/j.resuscitation.2018.12.002.

8. Lascarrou J-B, Merdji H, Le Gouge A, Colin G, Grillet G, Girardie P, et al. Targeted temperature management for cardiac arrest with nonshockable rhythm. N Engl J Med. 2019;381(24):2327-37. https://doi.org/10.1056/ NEJMoa1906661.

9. Kirkegaard H, Søreide E, de Haas I, Pettilä V, Taccone FS, Arus U, et al. Targeted temperature management for 48 vs 24 hours and neurologic outcome after out-of-hospital cardiac arrest: a randomized clinical trial. JAMA. 2017;318(4):341-50. https://doi.org/10.1001/jama.2017.8978.

10. De Fazio C, Skrifvars MB, Søreide E, Creteur J, Grejs AM, Kjærgaard J, et al. Intravascular versus surface cooling for targeted temperature management after out-of-hospital cardiac arrest: an analysis of the TTH48 trial. Crit Care. 2019;23(1):61. https://doi.org/10.1186/s13054-019-2335-7.

11. Nolan JP, Sandroni C, Böttiger BW, Cariou A, Cronberg T, Friberg H, et al. European Resuscitation Council and European Society of Intensive Care Medicine guidelines 2021: post-resuscitation care. Intensive Care Med. 2021; 47(4):369-421. https://doi.org/10.1007/s00134-021-06368-4. 
12. Kuczynski AM, Marzoughi S, Al Sultan AS, Colbourne F, Menon BK, van Es ACGM, et al. Therapeutic hypothermia in acute ischemic stroke-a systematic review and meta-analysis. Curr Neurol Neurosci Rep. 2020;20(5):13. https:// doi.org/10.1007/s11910-020-01029-3.

13. van der Worp HB, Macleod MR, Bath PM, Bathula R, Christensen H, Colam B, et al. Therapeutic hypothermia for acute ischaemic stroke. Results of a European multicentre, randomised, phase III clinical trial. Eur Stroke J. 2019; 4(3):254-62. https://doi.org/10.1177/2396987319844690.

14. Soar J, Callaway CW, Aibiki M, Böttiger BW, Brooks SC, Deakin CD, et al. Part 4: Advanced life support: 2015 International Consensus on Cardiopulmonary Resuscitation and Emergency Cardiovascular Care Science with Treatment Recommendations. Resuscitation. 2015;95:e71-120 https://doi.org/10.1016/j. resuscitation.2015.07.042

15. Peberdy MA, Callaway CW, Neumar RW, Geocadin RG, Zimmerman JL, Donnino M, et al. Part 9: post-cardiac arrest care: 2010 American Heart Association Guidelines for Cardiopulmonary Resuscitation and Emergency Cardiovascular Care. Circulation. 2010;122(18_suppl_3):S768-86. https://doi. org/10.1161/CIRCULATIONAHA.110.971002.

16. Bernard SA, Smith K, Cameron P, Masci K, Taylor DM, Cooper DJ, et al. Induction of prehospital therapeutic hypothermia after resuscitation from nonventricular fibrillation cardiac arrest*. Crit Care Med. 2012;40(3):747-53. https://doi.org/10.1097/CCM.0b013e3182377038.

17. Nie C, Dong J, Zhang P, Liu X, Han F. Prehospital therapeutic hypothermia after out-of-hospital cardiac arrest: a systematic review and meta-analysis. Am J Emerg Med. 2016;34(11):2209-16. https://doi.org/10.1016/j.ajem.2016. 09.007.

18. Kämäräinen A, Virkkunen I, Tenhunen J, Yli-Hankala A, Silfvast T. Prehospital therapeutic hypothermia for comatose survivors of cardiac arrest: a randomized controlled trial. Acta Anaesthesiol Scand. 2009;53(7):900-7. https://doi.org/10.1111/j.1399-6576.2009.02015.x.

19. Safar P, Xiao F, Radovsky A, Tanigawa K, Ebmeyer U, Bircher N, et al. Improved cerebral resuscitation from cardiac arrest in dogs with mild hypothermia plus blood flow promotion. Stroke. 1996;27(1):105-13. https:// doi.org/10.1161/01.str.27.1.105.

20. Strapazzon G, Procter E, Paal P, Brugger H. Pre-hospital core temperature measurement in accidental and therapeutic hypothermia. High Alt Med Biol. 2014;15(2):104-11. https://doi.org/10.1089/ham.2014.1008.

21. McCarthy PW, Heusch Al. The vagaries of ear temperature assessment. J Med Eng Technol. 2006;30(4):242-51. https://doi.org/10.1080/03091 900600711415.

22. Benzinger TH, Taylor GW. Cranial measurements of internal temperature in man. Temperature - Its Measurement and Control in Science and Industry, vol. 3. New York: Reinhold; 1963. p. 111-20.

23. Lorr D, Lund A, Fredrikson M, Secher NH. Tympanic membrane temperature decreases during head up tilt: relation to frontal lobe oxygenation and middle cerebral artery mean blood flow velocity. Scand J Clin Lab Invest. 2017;77(8):587-91. https://doi.org/10.1080/00365513.2017.1371323.

24. Paal P, Brugger $H$, Strapazzon G. Accidental hypothermia. Handb Clin Neurol. 2018;157:547-63 https://doi.org/10.1016/B978-0-444-64074-1. 00033-1.

25. Strapazzon G, Procter E, Putzer G, Avancini G, Dal Cappello T, Überbacher N, et al. Influence of low ambient temperature on epitympanic temperature measurement: a prospective randomized clinical study. Scand J Trauma Resusc Emerg Med. 2015;23(1):90. https://doi.org/10.1186/s13049-015-0172-5.

26. Budidha K, Kyriacou PA. In vivo investigation of ear canal pulse oximetry during hypothermia. J Clin Monit Comput. 2018;32(1):97-107. https://doi. org/10.1007/s10877-017-9975-4.

27. Schmäl F, Loh-van den Brink M, Stoll W. Effect of the status after ear surgery and ear pathology on the results of infrared tympanic thermometry. Eur Arch Otorhinolaryngol. 2006;263(2):105-10. https://doi.org/10.1007/s00405005-0966-6.

28. Tricco AC, Lillie E, Zarin W, O'Brien KK, Colquhoun H, Levac D, et al. PRISMA Extension for Scoping Reviews (PRISMA-SCR): Checklist and Explanation. Ann Intern Med. 2018;169(7):467-73. https://doi.org/10.7326/M18-0850.

29. Peters MDJ. In no uncertain terms: the importance of a defined objective in scoping reviews. JBI Database System Rev Implement Rep. 2016;14(2):1-4. https://doi.org/10.11124/jbisrir-2016-2838.

30. Munn Z, Peters MDJ, Stern C, Tufanaru C, McArthur A, Aromataris E. Systematic review or scoping review? Guidance for authors when choosing between a systematic or scoping review approach. BMC Med Res Methodol. 2018;18(1):143. https://doi.org/10.1186/s12874-018-0611-x.
31. Ouzzani M, Hammady H, Fedorowicz Z, Elmagarmid A. Rayyan—a web and mobile app for systematic reviews. Syst Rev. 2016;5. https://doi.org/10.1186/ s13643-016-0384-4(1):210.

32. Bagić A, Theodore WH, Boudreau EA, Bonwetsch R, Greenfield J, Elkins W, et al. Towards a non-invasive interictal application of hypothermia for treating seizures: a feasibility and pilot study. Acta Neurol Scand. 2008; 118(4):240-4. https://doi.org/10.1111/j.1600-0404.2008.01008.x.

33. Kallmünzer B, Beck A, Schwab S, Kollmar R. Local head and neck cooling leads to hypothermia in healthy volunteers. Cerebrovasc Dis. 2011;32(3): 207-10. https://doi.org/10.1159/000329376.

34. Koehn J, Wang R, de Rojas LC, Kallmünzer B, Winder K, Köhrmann M, et al. Neck cooling induces blood pressure increase and peripheral vasoconstriction in healthy persons. Neurol Sci. 2020;41(9):2521-9. https:// doi.org/10.1007/s10072-020-04349-x.

35. Koehn J, Kollmar R, Cimpianu C-L, Kallmünzer B, Moeller S, Schwab S, et al. Head and neck cooling decreases tympanic and skin temperature, but significantly increases blood pressure. Stroke. 2012;43(8):2142-8. https://doi. org/10.1161/STROKEAHA.112.652248.

36. Zweifler RM, Voorhees ME, Mahmood MA, Parnell M. Rectal temperature reflects tympanic temperature during mild induced hypothermia in nonintubated subjects. J Neurosurg Anesthesiol. 2004;16(3):232-5. https:// doi.org/10.1097/00008506-200407000-00008.

37. Zweifler RM, Voorhees ME, Mahmood MA, Parnell M. Magnesium sulfate increases the rate of hypothermia via surface cooling and improves comfort. Stroke. 2004;35(10):2331-4. https://doi.org/10.1161/01.STR.00001411 61.63181.f1.

38. Zweifler RM, Voorhees ME, Mahmood MA, Alday DD. Induction and maintenance of mild hypothermia by surface cooling in non-intubated subjects. J Stroke Cerebrovasc Dis. 2003;12(5):237-43. https://doi.org/10.101 6/j.jstrokecerebrovasdis.2003.09.006.

39. Mahmood MA, Voorhees ME, Parnell M, Zweifler RM. Transcranial Doppler ultrasonographic evaluation of middle cerebral artery hemodynamics during mild hypothermia. J Neuroimaging. 2005;15(4):336-40. https://doi. org/10.1111/j.1552-6569.2005.tb00333.x.

40. Adams R, Koster RW. Burning issues: early cooling of the brain after resuscitation using burn dressings. A proof of concept observation. Resuscitation. 2008;78(2): 146-50. https://doi.org/10.1016/j.resuscitation.2008.03.005.

41. Doufas AG, Lin C-M, Suleman M-I, Liem EB, Lenhardt R, Morioka N, et al. Dexmedetomidine and meperidine additively reduce the shivering threshold in humans. Stroke. 2003;34(5):1218-23. https://doi.org/10.1161/01. STR.0000068787.76670.A4

42. Jackson K, Rubin R, Van Hoeck N, Hauert T, Lana V, Wang H, et al. The effect of selective head-neck cooling on physiological and cognitive functions in healthy volunteers. Transl Neurosci. 2015;6(1):131-8. https://doi.org/10.1515/ tnsci-2015-0012.

43. Wadhwa A, Sengupta P, Durrani J, Akça O, Lenhardt R, Sessler Dl, et al. Magnesium sulphate only slightly reduces the shivering threshold in humans. Br J Anaesth. 2005;94(6):756-62. https://doi.org/10.1093/bja/aei105.

44. Busch H-J, Eichwede F, Födisch M, Taccone FS, Wöbker G, Schwab T, et al. Safety and feasibility of nasopharyngeal evaporative cooling in the emergency department setting in survivors of cardiac arrest. Resuscitation. 2010;81(8):943-9. https://doi.org/10.1016/j.resuscitation.2010.04.027.

45. Callaway CW, Tadler SC, Katz LM, Lipinski CL, Brader E. Feasibility of external cranial cooling during out-of-hospital cardiac arrest. Resuscitation. 2002; 52(2):159-65. https://doi.org/10.1016/S0300-9572(01)00462-2.

46. Castrén M, Nordberg P, Svensson L, Taccone F, Vincent J-L, Desruelles D, et al. Intra-arrest transnasal evaporative cooling: a randomized, prehospital, multicenter study (PRINCE: Pre-ROSC IntraNasal Cooling Effectiveness). Circulation. 2010;122(7):729-36. https://doi.org/10.1161/CIRCULATIONAHA.1 09.931691.

47. Hasper D, Nee J, Schefold JC, Krueger A, Storm C. Tympanic temperature during therapeutic hypothermia. Emerg Med J. 2011;28(6):483-5. https://doi. org/10.1136/emj.2009.090464.

48. Hachimi-Idrissi S, Corne L, Ebinger G, Michotte Y, Huyghens L, HachimiIdrissi $S$, et al. Mild hypothermia induced by a helmet device: a clinical feasibility study. RESUSCITATION. 2001;51(3):275-81. https://doi.org/10.1016/ S0300-9572(01)00412-9.

49. Islam S, Hampton-Till J, Watson N, Mannakkara NN, Hamarneh A, Webber T, et al. Early targeted brain COOLing in the cardiac CATHeterisation laboratory following cardiac arrest (COOLCATH). Resuscitation. 2015;97:61-7. https://doi.org/10.1016/j.resuscitation.2015.09.386. 
50. Krizanac D, Stratil P, Hoerburger D, Testori C, Wallmueller C, Schober A, et al. Femoro-iliacal artery versus pulmonary artery core temperature measurement during therapeutic hypothermia: an observational study. Resuscitation. 2013;84(6):805-9. https://doi.org/10.1016/j.resuscitation.2 012.11 .022$.

51. Shin J, Kim J, Song K, Kwak Y. Core temperature measurement in therapeutic hypothermia according to different phases: comparison of bladder, rectal, and tympanic versus pulmonary artery methods. Resuscitation. 2013;84(6):810-7. https://doi.org/10.1016/j.resuscitation.2 012.12.023.

52. Stratil P, Wallmueller C, Schober A, Stoeckl M, Hoerburger D, Weiser C, et al. Seasonal variability and influence of outdoor temperature on body temperature of cardiac arrest victims. Resuscitation. 2013;84(5):630-4. https://doi.org/10.1016/j.resuscitation.2012.09.027.

53. Takeda Y, Kawashima T, Kiyota K, Oda S, Morimoto N, Kobata H, et al. Feasibility study of immediate pharyngeal cooling initiation in cardiac arrest patients after arrival at the emergency room. Resuscitation. 2014;85(12): 1647-53. https://doi.org/10.1016/j.resuscitation.2014.09.014.

54. Wandaller C, Holzer M, Sterz F, Wandaller A, Arrich J, Uray T, et al. Head and neck cooling after cardiac arrest results in lower jugular bulb than esophageal temperature. Am J Emerg Med. 2009;27(4):460-5. https://doi. org/10.1016/j.ajem.2008.03.036.

55. Zeiner A, Holzer M, Sterz F, Behringer W, Schörkhuber W, Müllner M, et al. Mild resuscitative hypothermia to improve neurological outcome after cardiac arrest: a clinical feasibility trial. Stroke. 2000;31(1):86-94. https://doi. org/10.1161/01.STR.31.1.86.

56. Ko Y, Jung JY, Kim H-T, Lee J-Y. Auditory canal temperature measurement using a wearable device during sleep: comparisons with rectal temperatures at 6, 10, and $14 \mathrm{~cm}$ depths. J Therm Biol. 2019;85:102410. https://doi.org/1 0.1016/j.jtherbio.2019.102410.

57. Skulec R, Truhlár A, Seblová J, Dostál P, Cerný V. Pre-hospital cooling of patients following cardiac arrest is effective using even low volumes of cold saline. Crit Care. 2010;14(6):R231. https://doi.org/10.1186/cc9386.

58. Storm C, Schefold JC, Kerner T, Schmidbauer W, Gloza J, Krueger A, et al. Prehospital cooling with hypothermia caps (PreCoCa): a feasibility study. Clin Res Cardiol. 2008;97(10):768-72. https://doi.org/10.1007/s00392-008-0678-1.

59. Erlinge D, Götberg M, Lang I, Holzer M, Noc M, Clemmensen P, et al. Rapid endovascular catheter core cooling combined with cold saline as an adjunct to percutaneous coronary intervention for the treatment of acute myocardial infarction: The CHILL-MI trial: a randomized controlled study of the use of central venous catheter core cooling combined with cold saline as an adjunct to percutaneous coronary intervention for the treatment of acute myocardial infarction. J Am Coll Cardiol. 2014;63:1857-65.

60. Testori C, Beitzke D, Mangold A, Sterz F, Loewe C, Weiser C, et al. Out-ofhospital initiation of hypothermia in ST-segment elevation myocardial infarction: a randomised trial. Heart. 2019;105(7):531-7. https://doi.org/1 0.1136/heartjnl-2018-313705.

61. Abou-Chebl A, Sung G, Barbut D, Torbey M. Local brain temperature reduction through intranasal cooling with the RhinoChill device: preliminary safety data in brain-injured patients. Stroke. 2011;42(8):2164-9. https://doi. org/10.1161/STROKEAHA.110.613000.

62. Poli S, Purrucker J, Priglinger M, Ebner M, Sykora M, Diedler J, et al. Rapid Induction of COOLing in Stroke Patients (iCOOL1): a randomised pilot study comparing cold infusions with nasopharyngeal cooling. Crit Care. 2014; 18(5):582. https://doi.org/10.1186/s13054-014-0582-1.

63. Poli S, Purrucker J, Priglinger M, Diedler J, Sykora M, Popp E, et al. Induction of cooling with a passive head and neck cooling device: effects on brain temperature after stroke. Stroke. 2013;44(3):708-13. https://doi.org/10.1161/ STROKEAHA.112.672923.

64. Kammersgaard LP, Rasmussen BH, Jørgensen HS, Reith J, Weber U, Olsen TS. Feasibility and safety of inducing modest hypothermia in awake patients with acute stroke through surface cooling: a case-control study: the Copenhagen Stroke Study. Stroke. 2000;31(9):2251-6. https://doi.org/10.11 61/01.str.31.9.2251

65. Kollmar R, Schellinger PD, Steigleder T, Köhrmann M, Schwab S. Ice-cold saline for the induction of mild hypothermia in patients with acute ischemic stroke: a pilot study. Stroke. 2009;40(5):1907-9. https://doi.org/1 0.1161/STROKEAHA.108.530410.

66. Sund-Levander M, Grodzinsky E. Assessment of body temperature measurement options. Br J Nurs. 2013;22(942):944-50 https://doi.org/10.12 968/bjon.2013.22.16.942
67. Kammersgaard LP, Jørgensen HS, Rungby JA, Reith J, Nakayama H, Weber UJ, et al. Admission body temperature predicts long-term mortality after acute stroke: the Copenhagen Stroke Study. Stroke. 2002;33(7):1759-62. https://doi.org/10.1161/01.str.0000019910.90280.f1.

68. Uleberg O, Eidstuen S, Vangberg G, Skogvoll E. Temperature measurements in trauma patients: is the ear the key to the core? Scand J Trauma Resusc Emerg Med. 2015;23. https://doi.org/10.1186/s13 049-015-0178-z(1):101.

69. Skaiaa SC, Brattebø G, Aßmus J, Thomassen $\varnothing$. The impact of environmental factors in pre-hospital thermistor-based tympanic temperature measurement: a pilot field study. Scand J Trauma Resusc Emerg Med. 2015; 23(1):72. https://doi.org/10.1186/s13049-015-0148-5.

70. Lee SM, Williams WJ, Fortney Schneider SM. Core temperature measurement during supine exercise: esophageal, rectal, and intestinal temperatures. Aviat Space Environ Med. 2000;71:939-45.

71. Lim CL, Byrne C, Lee JK. Human thermoregulation and measurement of body temperature in exercise and clinical settings. Ann Acad Med Singap. 2008;37:347-53.

72. Wilkinson DM, Carter JM, Richmond VL, Blacker SD, Rayson MP. The effect of cool water ingestion on gastrointestinal pill temperature. Med Sci Sports Exerc. 2008;40(3):523-8. https://doi.org/10.1249/MSS.0b013e31 815 cc43e.

73. Gagnon D, Lemire BB, Jay O, Kenny GP. Aural canal, esophageal, and rectal temperatures during exertional heat stress and the subsequent recovery period. J Athl Train. 2010;45(2):157-63. https://doi.org/10.4085/1062-6050-4 5.2.157.

74. $\mathrm{Ng} \mathrm{D.} \mathrm{Infrared} \mathrm{ear} \mathrm{thermometers} \mathrm{versus} \mathrm{rectal} \mathrm{thermometers.} \mathrm{Lancet.} \mathrm{2002;}$ 360(9348):1881. https://doi.org/10.1016/S0140-6736(02)11739-9.

75. Robinson J, Charlton J, Seal R, Spady D, Joffres MR. Oesophageal, rectal, axillary, tympanic and pulmonary artery temperatures during cardiac surgery. Can J Anaesth. 1998;45(4):317-23. https://doi.org/10.1007/BF03 012021.

76. Akata T, Setoguchi H, Shirozu K, Yoshino J. Reliability of temperatures measured at standard monitoring sites as an index of brain temperature during deep hypothermic cardiopulmonary bypass conducted for thoracic aortic reconstruction. J Thoracic Cardiovasc Surg 2007;133:1559-1565.e2. https://doi.org/10.1016/j.jtcvs.2006.11.031.

77. Li H, Yang Z, Liu Y, Wu Z, Pan W, Li S, et al. Is esophageal temperature better to estimate brain temperature during target temperature management in a porcine model of cardiopulmonary resuscitation? Biomed Res Int. 2017;2017:1279307 https://doi.org/10.11 55/2017/1279307.

78. Stone JG, Young WL, Smith CR, Solomon RA, Wald A, Ostapkovich N, et al. Do standard monitoring sites reflect true brain temperature when profound hypothermia is rapidly induced and reversed? Anesthesiology. 1995;82(2): 344-51. https://doi.org/10.1097/00000542-199502000-00004.

79. Kaukuntla H, Harrington D, Bilkoo I, Clutton-Brock T, Jones T, Bonser RS. Temperature monitoring during cardiopulmonary bypass--do we undercool or overheat the brain? Eur J Cardiothorac Surg. 2004;26(3):580-5. https://doi. org/10.1016/j.ejcts.2004.05.004.

80. Masè M, Micarelli A, Strapazzon G. Hearables: new perspectives and pitfalls of in-ear devices for physiological monitoring. A scoping review. Front Physiol 2020;11. https://doi.org/10.3389/fphys.2020.568886, 11.

81. Johnston NJ, King AT, Protheroe R, Childs C. Body temperature management after severe traumatic brain injury: methods and protocols used in the United Kingdom and Ireland. Resuscitation. 2006;70(2):254-62. https://doi.org/10.1016/j.resuscitation.2006.02.010.

82. Kirk D, Rainey T, Vail A, Childs C. Infra-red thermometry: the reliability of tympanic and temporal artery readings for predicting brain temperature after severe traumatic brain injury. Crit Care. 2009;13(3):R81. https://doi.org/1 $0.1186 /$ cc7898.

83. Yeoh WK, Lee JKW, Lim HY, Gan CW, Liang W, Tan KK. Re-visiting the tympanic membrane vicinity as core body temperature measurement site. PLoS One. 2017;12(4):e0174120 https:/doi.org/10.1371/journal.pone.0174120.

84. Harris B, Andrews PJD, Murray GD, Forbes J, Moseley O. Systematic review of head cooling in adults after traumatic brain injury and stroke. Health Technol Assess. 2012;16(45). https://doi.org/10.3310/hta16450.

85. Karaszewski B, Thomas RGR, Dennis MS, Wardlaw JM. Temporal profile of body temperature in acute ischemic stroke: relation to stroke severity and outcome. BMC Neurol. 2012;12(1):123. https://doi.org/10.1186/1471-23 77-12-123. 
86. Laptook AR, Shalak L, Corbett RJ. Differences in brain temperature and cerebral blood flow during selective head versus whole-body cooling. Pediatrics. 2001;108(5):1103-10. https://doi.org/10.1542/peds.108.5.1103.

87. Ring EFJ, McEvoy H, Jung A, Zuber J, Machin G. New standards for devices used for the measurement of human body temperature. J Med Eng Technol. 2010;34(4):249-53. https://doi.org/10.3109/03091901003663836.

\section{Publisher's Note}

Springer Nature remains neutral with regard to jurisdictional claims in published maps and institutional affiliations.

Ready to submit your research? Choose BMC and benefit from:

- fast, convenient online submission

- thorough peer review by experienced researchers in your field

- rapid publication on acceptance

- support for research data, including large and complex data types

- gold Open Access which fosters wider collaboration and increased citations

- maximum visibility for your research: over $100 \mathrm{M}$ website views per year

At $\mathrm{BMC}$, research is always in progress.

Learn more biomedcentral.com/submissions 